\title{
Survey of medical centers points to funding gaps
}

Improved patient care has always been the primary goal of biomedical research. But as the debate over health care reform intensifies, questions about exactly how such research translates to patient care and how this research should be funded have moved to the forefront. A paper published in September aimed to address some of these questions (J. Am. Med. Assoc. 302, 969-976; 2009). The report, based on a 2007 survey, was one of the largest efforts to evaluate life sciences research in terms of category and funding sources.

The study authors surveyed close to 2,000 researchers at 50 academic medical centers around the US. They evaluated all categories of biomedical research-from basic bench work to clinical trials-but they were particularly interested in a category they call health services, which includes clinical epidemiology and comparative effectiveness research, a field geared toward identifying which medical treatments work best for patients.

An analysis found that, overall, principal investigators secured $\$ 410,755$ in total annual research funding on average. The vast majority of survey respondents had received research funding from government and other outside sources. But nearly half of the 107 health services researchers surveyed had no source of funding aside from their university employers. "If you're serious about healthcare reform, epidemiology and comparative effectiveness research are key," says Eric Campbell, director of the Institute for Health Policy at Massachusetts General Hospital and coauthor of the study. "We need a nimble, conflict-free health services work force making decisions based on effectiveness."

More than $20 \%$ of the researchers in the study reported receiving industry funding. Not surprisingly, the majority of industrysupported researchers were in the clinical trials category, but about $25 \%$ of translational researchers and $13 \%$ of health services researchers also reported industry funding. Funding from academic medical centers has its own problems, Campbell points out. "Most of that funding comes from the patients who visit the university hospitals," he says. "That's a very uncoordinated way of funding biomedical research. There has got to be something more efficient."

Last January, the US Congress set aside over $\$ 1$ billion for comparative effectiveness research from its economic stimulus package.
Out of that $\$ 1$ billion, $\$ 400$ million went to the US National Institutes of Health, and another $\$ 400$ million went to set up a federal office dedicated to comparative research.

How much the stimulus money will boost health services research remains to be seen, but Campbell and his coauthor, Darren Zinner of Brandeis University, are cautiously optimistic. "The question is whether the stimulus money will ultimately be additive or will take away from existing funding," says Zinner.

Campbell is more concerned about what will happen next year, after the stimulus money has been spent. "It takes years to train a health services work force, so we'll see what happens at the end of the year when that money goes away," he says.

Erica Westly, New York

\section{Infections linked to prostate cancer}

New research strengthens a possible link between a recently identified human retrovirus and prostate cancer-though a causal connection is far from certain. Scientists at the University of Utah in Salt Lake found evidence of the xenotropic murine leukemia virusrelated virus, XMRV, in $27 \%$ of 334 prostate cancer biopsies. XMRV was associated with the aggressive form of the disease (Proc. Natl. Acad. Sci. USA doi:10.1073/pnas.0906922106; 2009).

Researchers say that this discovery might have implications for prevention and treatment. "If further connections are found, then preventing viral infection would be a first step," says lead author on the new paper Ila Singh of the University of Utah. She adds that a vaccine for XMRV could be developed, and antiretroviral drugs could be tested to treat infection.

XMRV is a member of the gamma retrovirus family, known to produce cancer in animals, but not in humans (Proc. Natl. Acad. Sci. USA 104, 14491450; 2007). It was first identified two years ago by Robert Silverman of the Cleveland Clinic in Ohio and his colleagues at the University of San Francisco in California (PLoS Pathog. 2, e25; 2006).

"The new finding of XMRV in malignant epithelial cells suggests it may be involved in prostate cancer development, and not just a passenger virus, although that remains to be proven," says Silverman, who was not involved in the new study.

If a causal connection is found in future research, XMRV might serve as a useful marker to identify cases that would benefit from treatment, as opposed to those that grow very slowly and play no part in morbidity or mortality, says Singh.

Others recently found another infectious disease connection to prostate cancer. In a study of 673 subjects, scientists at the Harvard University School of Public Health found that men that had been infected with the sexually transmitted pathogen Trichomonas vaginalis had a more than twofold higher risk of aggressive prostate cancer ( $J$. Natl. Cancer Inst. doi:10.1093/jnci/ djp306; 2009).

Vicki Brower, New York 